\section{Questión}

Periodismo / Comunicación ISSN 1669-6581

Hoy la radio debe acercarse a la audiencia

Yesica Marina Bernardou

Question/Cuestión, Vol. 2, № 66, Agosto 2020

ISSN 1669-6581

https://perio.unlp.edu.ar/ojs/index.php/question/index

IICom-FPyCS-UNLP

\title{
HOY LA RADIO DEBE ACERCARSE A LA AUDIENCIA
}

\section{TODAY THE RADIO MUST APPROACH THE AUDIENCE}

\section{Yesica Marina Bernardou}

Presidenta de CADERO - Cámara Argentina de Radios OnLine

Twitter:@CaderoOK

\section{Resumen}

Yesica Marina Bernardou describe las radios online, su evolución y examina el futuro de estas emisoras, que tienen a las redes y a los teléfonos inteligentes como aliados.

\section{Palabras clave}

Radios online, Contenidos, Gestión, Tecnología, Futuro 


\section{Abstract}

Yesica Marina Bernardou describes online radios, their evolution and examines the future of these stations, which have networks and smartphones as allies.

\section{Keywords}

Online radios, Contents, Management, Technology, Future

\section{Enlace}

https://go.ivoox.com/rf/55778438 